\title{
Subsídio hídrico fornecido por substratos alternativos usados na germinação in vitro de Pinus taeda L.
}

\author{
Water supply offered by alternative substrates used in in vitro Pinus taeda L. germination
}

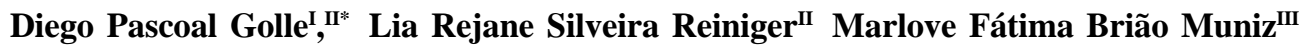 \\ Aline Ritter Curti ${ }^{\text {II }}$ Felippe Corrêa da Rosa ${ }^{\text {II }}$
}

\begin{abstract}
- NOTA -
RESUMO

Os objetivos deste trabalho foram avaliar o suprimento hídrico fornecido por diferentes substratos alternativos e analisar sua eficiência na sanidade e na germinação in vitro de sementes de Pinus taeda $\mathbf{L}$. Sementes foram inoculadas em papel filtro, algodão hidrófilo e meio ágar-água. Foi avaliada a absorção de água pelas sementes

was determined. Water absorption, based on the percentage increase which occurred in the weight of seeds, was higher in filter paper and hydrophile cotton. The best germination rates were obtained with filter paper and agar-water. However, agarwater presented the highest contamination rates. Due to water loss in the substrate filter-paper during cultivation, it is suggested the use of cotton because of the low contamination rates observed.
\end{abstract} por três, seis, nove, 24, 48 e 72 horas. Posteriormente, aos 21 dias de cultivo, foi determinada a contaminação por microrganismos. A absorção de água, com base no aumento percentual que ocorreu na massa das sementes, foi superior em papel filtro e algodão hidrófilo. Os melhores percentuais de germinação foram obtidos com papel filtro e ágar-água. Contudo, este último apresentou as maiores taxas de contaminação. Devido à perda de água no substrato papel filtro no decorrer do tempo, recomenda-se o uso de algodão hidrófilo em função dos baixos índices de contaminação observados.

Palavras-chave: sementes florestais, cultura de tecidos, contaminação.

\section{ABSTRACT}

The aim of this study was to assess the water supply provided by different alternative substrates as well as to analyze its efficiency in the sanity and in the in vitro germination of Pinus taeda $\mathbf{L}$. seeds. The seeds were inoculated in filter paper, hydrophile cotton and agar-water medium. Water absorption by seeds was assessed for 3, 6, 9, 24, 48 and $72 \mathrm{~h}$ and, later, at 21 days of cultivation and contamination by microorganisms
Key words: forestry seeds, tissue culture, contamination.

Pinus taeda L. está entre as espécies mais utilizadas na formação de povoamentos silviculturais, com plantios que chegam a totalizar, no Brasil, dois milhões de hectares (SELLE et al., 1994). É necessário, no entanto, que a produção florestal nacional seja ampliada, sendo, para isso, importante o desenvolvimento de tecnologias, tais como a produção de clones melhorados (IPEF, 2002).

De forma geral, em espécies do gênero Pinus spp., a clonagem in vitro é realizada por embriogênese somática. KIM \& MOON (2007) testaram embriões zigóticos de Pinus rigida x P. taeda quanto ao seu potencial para iniciar a formação de massa suspensora embriogênica, obtendo a maior frequência de formação de $1,1 \%$. Esses autores concluíram que mais estudos

'Programa de Pós-graduação em Engenharia Florestal, Centro de Ciências Rurais (CCR), Universidade Federal de Santa Maria (UFSM), Santa Maria, RS, Brasil.

"Departamento de Fitotecnia, CCR, UFSM, 97105-900, Santa Maria, RS, Brasil. E-mail: diegolle@yahoo.com.br. *Autor para correspondência.

IIIDepartamento de Defesa Fitossanitária, CCR, UFSM, Santa Maria, RS, Brasil. 
são necessários para a otimização do método. A competência morfogenética de embriões maduros de Pinus radiata foi avaliada por SÁNCHEZ-OLATE et al. (2008), os quais obtiveram $95 \%$ de germinação dos embriões e 100\% de sobrevivência. Em Pinus taeda, aspectos da embriogênese somática também foram estudados (TANG et al., 2001; e PULLMAN et al., 2003).

No entanto, os procedimentos laboratoriais necessários para a embriogênese são mais trabalhosos que a obtenção de plantas por organogênese direta. Esta pode ser obtida a partir de explantes oriundos de plantas germinadas in vitro, os quais apresentam juvenilidade. Para reduzir custos com a germinação in vitro, o uso de meios de cultura alternativos pode auxiliar na viabilização dos trabalhos. Deve-se considerar, porém, que esses substratos precisam ser capazes de oferecer as condições necessárias para que se inicie o processo germinativo. $\mathrm{O}$ trabalho objetivou avaliar o suprimento hídrico fornecido por diferentes meios alternativos em diferentes períodos de tempo e analisar a influência destes na germinação in vitro e na contaminação microbiana de sementes de Pinus taeda L.

Sementes foram inoculadas em frascos de vidro com capacidade para $150 \mathrm{~mL}$ contendo três diferentes substratos: três folhas de papel filtro umedecidas até atingirem três vezes o peso do papel; algodão hidrófilo $(0,600 \mathrm{~g})$ umedecido até o encharcamento; e meio de cultura água-ágar (0,07\%), na quantidade de $30 \mathrm{~mL}$. Os substratos foram previamente autoclavados por $20 \mathrm{~min}, \mathrm{a} 121^{\circ} \mathrm{C}$, exceto o papel filtro, que foi montado em câmara de fluxo, visando reduzir o ressecamento durante o processo de esterilização. As sementes não foram submetidas à desinfestação superficial para possibilitar a melhor observação da contaminação por microorganismos nos diferentes substratos.

O experimento foi conduzido em delineamento inteiramente casualizado, com 10 repetições compostas por 10 sementes cada uma. As unidades experimentais permaneceram em sala de cultivo com temperatura controlada de $25^{\circ} \mathrm{C} \pm 3$ e fotoperíodo de 16 horas, com intensidade luminosa de $20 \mu \mathrm{mol} \mathrm{m} \mathrm{m}^{-2} \mathrm{~s}^{-1}$, fornecida por lâmpadas fluorescentes brancas frias.

Analisou-se a absorção de água pelas sementes durante três, seis, nove, 24,48 e 72 horas, com base no aumento percentual que ocorreu na massa (g) das sementes. As avaliações foram realizadas nesses períodos visando observar a diferença entre os tratamentos qualitativos testados em cada um desses momentos, já que a informação mais relevante é a forma como se dá o condicionamento osmótico em cada substrato e, como é necessário mais tempo de contato das sementes com o meio para a germinação, é irrelevante saber, sem levar em consideração os substratos, em qual dos tempos houve maior suprimento de água. Aos 21 dias, realizaram-se as análises das contaminações fúngicas, bacterianas e da germinação in vitro (em \%). Os dados foram transformados para $\sqrt{x+0,5}$ e submetidos à análise de variância, e as médias foram comparadas pelo teste de Tukey, a 5\% de probabilidade de erro.

Em todos os tempos testados, exceto 72 horas, o substrato papel filtro mostrou-se superior ao ágar-água quanto ao condicionamento osmótico (Tabela 1). Já o substrato algodão hidrófilo, embora, eventualmente, tenha se comportado como intermediário, não diferindo dos demais, foi superior ao substrato ágar-água nos tempos de seis, nove e 48 horas. Reduções das porcentagens de fornecimento hídrico ocorreram após $48 \mathrm{~h}$ para o papel filtro, possivelmente pela dificuldade deste manter seus níveis de umidade. Decorridas $72 \mathrm{~h}$ da inoculação das sementes, não foram observadas diferenças estatísticas significativas entre os substratos.

É possível inferir que as sementes absorveram, inicialmente, água em grande quantidade, para iniciarem seu processo germinativo. Depois, quando foram ativados metabólitos e rotas bioquímicas essenciais à germinação, além da respiração da semente, essas taxas de absorção tenderam a entrar em estabilidade. Essa sequência de acontecimentos está de acordo com o que citam BORGES \& RENA (1993) sobre o processo de germinação, em que se pode salientar que quanto maior a embebição inicial, mais rapidamente será ativado o processo germinativo.

Quanto à germinação (Figura 1), papel filtro e ágar-água não diferiram significativamente, apresentando médias de germinação de 74 e 76\%, respectivamente. Esses resultados foram superiores aos obtidos com algodão hidrófilo (22\%). Tais resultados diferem dos obtidos com Adenanthera pavonina por FANTI \& PEREZ (1999), os quais, testando a germinação de sementes em substratos alternativos, não observaram diferenças entre papel filtro e algodão hidrófilo.

Quanto à contaminação fúngica, aos 21 dias (Figura 1), os tratamentos papel filtro e algodão hidrófilo foram significativamente superiores ao ágar-água, com valores de 8,0 e $100 \%$, respectivamente. Aparentemente, o algodão hidrófilo não constitui um ambiente apropriado ao desenvolvimento de fungos. Não se observou contaminação bacteriana nas sementes. Conforme GOLLE (2007), taxas baixas de contaminação são muito importantes na germinação in vitro de Pinus taeda, já que os tratamentos rotineiros 
Tabela 1 - Porcentual do aumento na massa de sementes de Pinus taeda L. pela absorção de água nos substratos: papel filtro, algodão hidrófilo e meio ágar-água. Avaliações após três, seis, nove, 24, 48 e 72 horas. Santa Maria-RS, UFSM, 2007.

\begin{tabular}{|c|c|c|c|}
\hline \multirow{2}{*}{ Substrato } & \multicolumn{3}{|c|}{----------------------Aumento na Massa das Sementes (\%) pela Absorção de Água--------------------- } \\
\hline & 3 horas & 6 horas & 9 horas \\
\hline Papel filtro & $22,87 a^{*}$ & $27,98 \mathrm{a}$ & $32,12 \mathrm{a}$ \\
\hline Algodão hidrófilo & $18,99 \mathrm{a} \mathrm{b}$ & $27,67 \mathrm{a}$ & 29,43 a \\
\hline 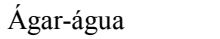 & $11,27 \mathrm{~b}$ & $17,59 \mathrm{~b}$ & $20,06 \mathrm{~b}$ \\
\hline $\mathrm{CV}(\%)$ & 20,3 & 15,57 & 14,71 \\
\hline Substrato & 24 horas & 48 horas & 72 horas \\
\hline Papel filtro & $31,63 \mathrm{a}$ & $29,39 \mathrm{a} \mathrm{b}$ & $30,51 \mathrm{a}$ \\
\hline Algodão hidrófilo & $30,09 \mathrm{a} \mathrm{b}$ & $32,45 \mathrm{a}$ & $32,57 \mathrm{a}$ \\
\hline Ágar-água & $21,08 \mathrm{~b}$ & $22,54 \mathrm{~b}$ & $24,36 \mathrm{a}$ \\
\hline CV $(\%)$ & 16,05 & 15,31 & 15,63 \\
\hline
\end{tabular}

*Médias não seguidas pela mesma letra na coluna diferem estatisticamente pelo teste de Tukey, a 5\% de probabilidade de erro.

de desinfestação superficial das sementes com álcool e hipoclorito de sódio apresentam efeito tóxico.

Pode-se concluir que existem diferenças importantes quanto ao suprimento hídrico fornecido por diferentes substratos às sementes de Pinus taeda L. Algodão hidrófilo e papel filtro podem ser considerados superiores quanto ao suprimento hídrico inicial e quanto à manutenção da sanidade durante a germinação, o que facilita a desinfestação dos explantes para trabalhos de cultura de tecidos a posteriori. $\mathrm{O}$ meio ágar-água, embora forneça bons índices de germinação, não é indicado pelo excesso de

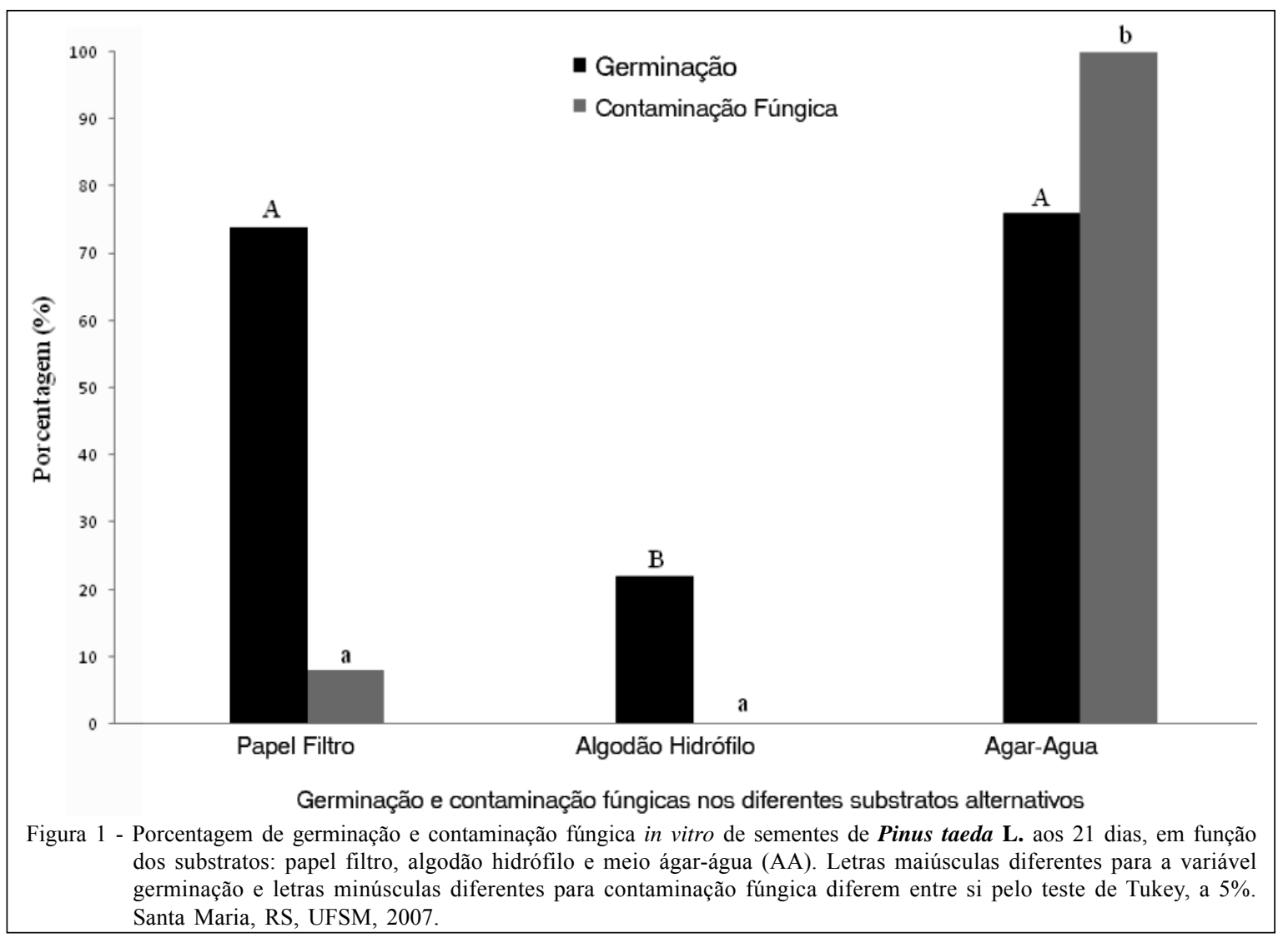

Ciência Rural, v.39, n.7, out, 2009. 
contaminação observado. Como o meio papel filtro perde umidade durante o decorrer do tempo, indica-se o uso de algodão hidrófilo e sugerem-se testes com tratamentos pré-germinativos, visando otimizar a germinação.

\section{REFERÊNCIAS}

BORGES, E.E.L.; RENA, A.B. Germinação de sementes: In: AGUIAR, I.B. et al. Sementes florestais tropicais. Brasília: Abrates, 1993. p.83-135.

FANTI, S.C.; PEREZ, S.C.J.G.A. Influência do substrato e do envelhecimento acelerado na germinação de olho-de-dragão (Adenanthera pavonina L. - Fabaceae). Revista Brasileira de Sementes, v.21, n.2, p.135-141, 1999.

GOLLE, D.P. Germinação in vitro de Pinus taeda L. a partir de sementes selecionadas. 2007. 98f. Dissertação (Mestrado em Engenharia Florestal) - Programa de Pósgraduação em Engenharia Florestal, Universidade Federal de Santa Maria, Santa Maria, RS.

IPEF. Instituto de Pesquisas e Estudos Florestais. Ciência e tecnologia no setor florestal brasileiro: diagnóstico, prioridades e modelo de financiamento - Relatório final. Piracicaba: Ministério da Ciência e Tecnologia, 2002. 12p.
KIM, Y.W.; MOON, H.K. Regeneration of plant by somatic embryogenesis in Pinus rigida $\times$ P. taeda. In vitro Cellular \& Developmental Biology - Plant, n.43, p.335-442, 2007. Disponível em: <http://dx.doi.org/10.1007/s11627-007-90456>. Acesso em 21 de out. 2008. doi: 10.1007/s11627-0079045-6.

PULLMAN, G.S. et al. Somatic embryogenesis in loblolly pine (Pinus taeda L.): improving culture initiation with abscisic acid and silver nitrate. Plant Cell Reports, v.22, p.85-95, 2003. Disponível em: <http://dx.doi.org/10.1007/s00299-003-0673y>. Acesso em 18 out. 2008. doi: 10.1007/s00299-003$0673-y$

SÁNCHEZ-OLATE, M. et al. Competencia morfogénica de embriones maduros de Pinus radiata cultivados in vitro y su relación com La posición del cono em el árbol. Bosque, v.29, n.3, p.212-216, 2008.

SELlE, G.L. et al. Classificação de sítio para Pinus taeda L. através da altura dominante, para a região de Cambará do Sul, RS, Brasil. Ciência Florestal, v.4, n.1, p.77-95, 1994.

TANG, W. et al. Genotypic control of high-frequency adventitious shoot regeneration via somatic organogenesis in loblolly pine. Plant Science, n.161, p.267-272, 2001. Disponível em: <http:/ /dx.doi.org/10.1016/S0168-9452(01)00394-6>. Acesso em 20 jul. 2007. doi: 10.1016/S0168-9452(01)00394-6. 